\title{
Adolescent Problematic Gaming and Domain-Specific Perceptions of Self
}

\author{
Devin J. Mills, McGill University, Montreal, Canada \\ Jessica Mettler, McGill University, Montreal, Canada \\ Michael J. Sornberger, Hull Services, Calgary, Canada \\ Nancy L. Heath, McGill University, Montreal, Canada
}

\begin{abstract}
Problematic video game use (PVGU) is an inability to meet personal and social responsibilities due to video gaming. It is estimated to affect 5 to $6 \%$ of adolescents. Research demonstrates greater video game engagement is associated with a poorer perception of self in several domains; however, the relation between PVGU and self-perception has not yet be examined. The present study explored this association using a sample of 758 Grade 7 adolescents $\left(55.1 \%\right.$ Female; $\mathrm{M}_{\text {age }}=12.34$ years; $S D=0.49$ years). Results revealed greater PVGU to be associated with a poorer perception of self within the behavioural conduct and close friendship domains. Similar differences emerged when examining reports of self-perception across the PVGU classifications (i.e., None, Minimal, At-Risk, Problematic). Unexpectedly, two interactions between gender and PVGU classifications were observed for the behavioural conduct and self-worth domains of self-perception. The discussion addresses the implications of these findings and points to areas of future research.
\end{abstract}

\section{KEYWORDS}

Adolescents, Domain-Specific, Gaming, Perceptions, Problematic Video Game Use, PVGU, Self

\section{INTRODUCTION}

Problematic video game use (PVGU) manifests itself in the inability to meet social and personal responsibilities. In the Diagnostic and Statistical Manual of Mental Disorders, Fifth Edition (DSM5; American Psychiatric Association, 2013), PVGU is proposed as an emerging construct meriting further study under the name of Internet Gaming Disorder, however, the proposal states that nonInternet video games may as well be included. Nine criterion are included with this proposal. Petry and colleagues (2014) provide a brief review of the proposed criteria which include all six components of Griffiths' (2005) biopsychosocial framework of behavioural addictions (salience, mood modification, conflict, relapse, withdrawal, and tolerance). Although individuals may report anywhere from zero to nine symptoms, the proposed cutoff to be considered as a "problematic gamer" is five or more symptoms. Research using representative samples as well as the DSM-5 proposed criteria has found PVGU may affect 5\% to 6\% of adolescents (Lemmens, Valkenburg, \& Gentile, 2015; Rehbein, Kliem, Baier, Mößle, \& Petry, 2015). More recently, research has begun to identify a variety of variables differentiating problematic gamers from other gamers, and even non-gamers. Building upon this area of research, Evans, Noam, Wertlieb, Paget, and Wolf (1994) suggest that a measure of self-perception may be helpful in identifying individuals' strengths and weaknesses from their own perspective. In the present study, reports of self-perception across several domains pertinent to the period of adolescence were explored in relation to the report of problematic gaming symptoms. The present paper is the first to explore self-perception within the emerging field of problematic gaming. 


\section{Video Games and Problematic Use of Video Games}

Video games are broadly defined as interactive games played on electronic devices. According to Granic, Lobel, and Engels (2013), a key element of this definition is interactive. That is, video game users directly affect not only the outcome of the game, but also the overall story. Video games may be played online, implying the use of the Internet, or offline, suggesting users are playing against a computer player or exploring the video game world. Video game users from around the world may join other video game users playing online creating a multiplayer experience, however, this is not always the case. For instance, some video games only exist online and do not provide a multiplayer experience. Moreover, offline games are frequently played with friends in same physical space. Therefore, the contrast between online versus offline video games does little to explain the significance of the video games in today's society.

The Entertainment Software Association (2013) reports 59\% of the total U.S. population play video games with additional research suggesting as much as $88 \%$ of U.S. youth between the ages of 8 and 19 years play video games at least occasionally (Gentile, 2009). In Asia, Gentile and colleagues (2011) found that over $80 \%$ of adolescents in Singapore play video games, and Ko, Yen, Chen, Chen, and Yen (2005) found that over $80 \%$ of adolescent males in Taiwan play video games. Thus, video games are a ubiquitous part of societies throughout the world.

Research focusing on the quantity of playing has explored several correlates. For instance, research by Anderson and colleagues (e.g., Anderson et al., 2010; Bushman \& Anderson, 2002) has demonstrated a possible link between exposure to violence in video games and measures of aggression. Other research has examined the quantity of video game use in association with academic performance (Hastings et al., 2009) and obesity (Mitchell, Rodriguez, Schmitz, \& Audrain-McGovern, 2013) suggesting lower academic performance and increased obesity are connected to higher quantities of gaming. Finally, an extensive research program by Kowert and colleagues (Bowman, Kowert, \& Cohen, 2015; Kowert, Domahidi, \& Quandt, 2014; Kowert \& Oldmeadow, 2014) has demonstrated that social characteristics of gamers may be predicted by their level of video game involvement (i.e., time spent playing, game variety, social identity toward video game community). In recent years, gaming research has moved away from focusing solely on the amount of video game use and attempted to understand how an addictive or problematic style of video game engagement manifests itself (e.g., King, Haagsma, Delfabbro, Gradisar, \& Griffiths, 2013; Sim, Gentile, Bricolo, Serpelloni, \& Gulamoydeen, 2012).

According to King and colleagues (2013), PVGU is most commonly described in the literature as an inability to control one's video game consumption, the experience of withdrawal-like symptoms (e.g., sadness or irritability) during periods of not playing, increased conflict in relationships, and decreased involvement in day-to-day responsibilities. The rationale for not including quantity of video game use as a symptom stems from a larger perspective that a disorder must be accompanied by negative outcomes (Griffiths, 2009). However, previous research has consistently found amount of time spent playing and the number of reported symptoms to be positively correlated ranging from .20 (Lemmens et al., 2015) to .30 (Gentile et al., 2011).

Prior research has shown PVGU in adolescence to be associated with several indicators of maladaptive functioning such as increased loneliness (Lemmens et al., 2011), greater impulsivity (Gentile et al., 2011), and elevated aggression (Desai, Krishnan-Sarin, Cavallo, \& Potenza, 2010; Gentile et al., 2011; Lemmens et al., 2015). Additionally, Spekman, Konijn, Roelofsma, and Griffiths (2013) found PVGU was positively correlated $(r=.65)$ with participants' own feelings of being addicted to video games, suggesting a level of cognitive awareness of the effect of one's own video game use. In a study by Rehbein, Kleimann, and Mössle (2010), groups of gamers were classified 
by their level of PVGU reported. A logistic regression revealed the strongest predictor of belonging to the problematic group was a perception of only being successful in video games compared to other recreational activities. Other predictors included social competence, anxiety within the school environment, and the use of gaming as a coping mechanism. A final note is the persistent gender difference within the literature. Prior research has shown males report a greater number of symptoms than females (Gentile et al., 2011; Lemmens, Valkenburg, \& Peter, 2011; Tejeiro Salguero \& Bersabé Morán, 2002), therefore, research examining PVGU should account for an expected gender difference. Taken together, the literature suggests PVGU to be a serious concern. The present study builds upon previous research by examining the association between PVGU and adolescents' self-perception.

\section{Self-Perception}

Self-perception (or self-concept) is a multidimensional construct of self-esteem (Harter, 1990; Marsh \& Shavelson, 1985). The construct contains a general perception of oneself (i.e., self-worth) as well as one's self-evaluations of perceived competence within a variety of specific domains such as scholastic, social or athletic. Perceptions of self-worth are informed by individuals' opinions of their own domain-specific competence, which are most commonly derived from comparing one's ability to that of others (Harter, 1997). Moreover, as individuals mature, existing domains are further differentiated corresponding with increased cognitive ability suggesting individuals' perceptions of themselves are not time invariant constructs (Harter, 2003, 2011; Marsh \& Shavelson, 1985). Research shows that adolescents (13 to 18 years) are able to differentiate among eight domains of self-perception (athletic competence, behavioural conduct, close friendship, physical appearance, social competence, scholastic competence, job competence, and romantic appeal) and provide a general assessment of their own self-worth (Harter, 1988). Similar to the literature on PVGU, work in the area of self-perception has found a relatively consistent gender difference. A meta-analysis of 22 articles including reports from 19,379 children and adolescents by Wilgenbusch and Merrell (1999) revealed a moderate overall effect size for gender within the athletic competence and physical appearance domains suggesting boys tend to perceive themselves more positively in these areas compared to their female peers. On the other hand, girls tend to perceive themselves more positively in their ability to continue and maintain close friendships.

\section{PVGU and Self-Perception}

Research has not yet examined the construct of self-perception in conjunction with a measure of PVGU, however, two previous studies have found initial evidence suggesting an increased quantity of video game use during adolescence may be associated with domains of self-perceptions. For instance, Funk and Buchman (1996) found greater video game use was associated with a lower perception of self in the scholastic competence, social acceptance, athletic competence, behavioural conduct domains as well as a lower overall perception of self-worth; however, their results are limited to only female adolescents. In another study by Jackson, von Eye, Fitzgerald, Zhao, and Witt (2010), greater video game use by both male and female adolescents was correlated with a lower perception of self in the scholastic competence domain as well as a lower overall perception of self-worth. Given the previous evidence of the relation between time spent playing and PVGU (Gentile et al., 2011; Lemmens et al., 2015) and the observed negative association between perceptions of self within several domains of selfperception, it is likely that PVGU may be also related to one or more domains of self-perception. The results from such work would represent a first step in understanding how problematic gamers perceive their own competencies and abilities across domains, which may guide future research in identifying potential interventions for PVGU. However, such work should consider two methodological issues.

First, previous research has suggested that some amount of gaming may be associated with adaptive functioning, which might suggest that the association between PVGU and self-perception may not necessarily be linear. For instance, Durkin and Barber (2002) found that individuals reporting a low amount of use may actually report higher self-esteem, lower depressive moods, and even less 
disobedience compared to adolescents reporting either no video game use or high video game use. Second, gender differences in self-perception as well as in PVGU may confound the results. In line with recommendations from Sim and colleagues (2012), the association between PVGU and adolescent self-perception should be explored by examining differences among at least three groups as representing varying levels of PVGU symptomology, which would further allow for gender to be added as an additional factor. Sim and colleagues recommend three classifications (minimal, at-risk, and problematic), however, a zero symptom classification could be added as a control group. Thus, these two issues are addressed by applying a factorial study design whereby participants are classified following the scoring of their PVGU.

\section{Present Study}

Previous research has demonstrated greater PVGU to be associated with a variety of indicators related to a lower perception of self in the social acceptance domain (Lemmens et al., 2011), behavioural conduct domain (Lemmens, Valkenburg, \& Peter, 2009), scholastic competence domain (Gentile et al., 2011), as well as other domains of self-perception when assessed in isolation. However, the present study attempts to explore these associations simultaneously making it difficult to create hypotheses regarding specific domains of self-perception given the previous literature. Therefore, the following two research objectives pertaining to adolescents' PVGU and their perceptions of self are largely exploratory in nature. The first objective was to assess the association between reports of PVGU and domains of self-perception. It was hypothesized (H1) that PVGU would be associated with a poorer perception of self in at least one or more domains of adolescents' self-perception. The second objective assesses for differences in adolescents' perception of themselves across these domains between males and females and among four PVGU classifications varying in the level of reported PVGU. Based on previous literature, it was hypothesized $(\mathrm{H} 2)$ that males would report a greater perception of self in the athletic competence and physical appearance domains, whereas, females would report a greater perception of self in the close friendship domain. Additionally, it was hypothesized $(\mathrm{H} 3)$ that classifications representing greater PVGU would report a poorer perception of self in at least one or more domains. Finally, due to the absence of literature regarding the possible interaction between gender and the PVGU classifications, no additional hypotheses were made.

\section{METHOD}

\section{Participants}

Participants were recruited from several English-speaking schools in the greater Montreal area. A sample of 897 Grade 7 adolescents (55.6\% Female; $M_{\text {age }}=12.35 \mathrm{yrs} ; S D=0.49 \mathrm{yrs}$ ) participated. Participants were excluded if they omitted more than two items on the Pathological Video Game Use Questionnaire (PVGQ; Sim et al., 2012) or more than one item on any of the Self-Perception Profile for Adolescents (SPPA; Harter, 1988) subscales. Eighty-one participants were excluded from the study for not submitting valid questionnaires. Therefore, the present study included data from a sample of 816 participants at Grade 7 (55.5\% Female; $M_{\text {age }}=12.35$ years; $S D=0.49$ years).

\section{Instruments}

\section{Pathological Video Game Use Questionnaire}

Sim and colleagues (2012) developed the 10-item PVGQ to assess the presence of PVGU. In line with other disorders in the DSM, each question is limited to the past 12 months. Participants respond using a trichotomous scale $(2=$ Yes; $1=$ Sometimes; $0=N o)$. An additional item was added to the instrument to assess arguments with parents over video game use (i.e., In the past year, have you argued with your parents about how much time you spend playing video games?). A higher score is indicative of increased problematic gaming. For the present sample, the Cronbach alphas was found to be adequate at Grade $7(\alpha=.76)$. 
Four a priori groups were created using total scores on the PVGQ measure. Although Sim and colleagues (2012) recommend the use of three groups (i.e., None/Minimal, At-Risk, Problematic), it was decided in the present study to split the None/Minimal Group into two groups in order to have a comparison group. In the None Group, individuals reported a score of zero, indicating an absence of any PVGU. In the Minimal Group, individuals reported scores ranging from 1 to 4 suggesting at least one and at most two symptoms of PVGU were present. In the At-Risk Group, individuals reported a score ranging from 5 to 9 demonstrating an endorsement of at least three and at most five symptoms of PVGU. Finally, individuals reporting a score of 10 or above were included in the Problematic Group indicating a report of five or more symptoms. The Problematic Group should not be interpreted as a representative sample of adolescents meeting the proposed cutoff for Internet Gaming Disorder, but those struggling with heightened PVGU.

\section{Self-Perception Profile for Adolescents}

Harter (1988) developed the 45-item SPPA to assess eight separate domains of self-perception (i.e., athletic competence, behavioral conduct, close friendship, physical appearance, social competence, scholastic competence, job competence, and romantic appeal) and an overall evaluation of one's self-worth. Five items assess each of the eight domains and overall self-worth. Harter describes the unique format of the SPPA as a structured alternative format. Each item consists of two contrasting statements. For instance, an item tapping participants' athletic competence states, "Some teenagers do very well at all kinds of sports BUT Other teenagers don't feel that they are very good when it comes to sports." Participants are asked to first pick the statement they feel most accurately describes how they perceive themselves and then rate whether the statement is sort of true for me or really true of me. If participants choose the positively worded sentence, then they are given a score of 3 for selecting sort of true for me or a score of 4 for selecting really true of me. If participants choose the negatively worded sentence, then they are given a score of 1 for selecting sort of true for me or a score of 2 for selecting really true of me. About half of the items present the positively worded sentence first and the other half present the negatively worded sentence first. Harter (1988) argues the format assists in lowering social desirability. Due to the young age of the students at the time the SPPA was administered, the romantic appeal and job competence domains of self-perception were not included for the present study. Cronbach alphas for the present sample ranged from .68 to .86 for each subscale of the SPPA suggesting adequate internal consistency.

\section{Procedure}

Students were presented with a description, and the associated risks, benefits, goals, objectives, methodology, and confidentiality agreements of the research project. Participation was incentivized with a raffle to win one of four $\$ 50$ gift cards to a popular retail store. The participants were made aware of their rights and told they could withdraw from the study at any point. Due to the age of the participants, students were provided with a project information letter and informed consent form to give to their parents. The students who returned signed consent forms, regardless of agreement to participate, received a small chocolate bar and were entered in a draw for one of two gift cards (valued at $\$ 100$ and \$200) to a local shopping mall.

The questionnaires were completed during a single session in the schools' cafeterias in groups by students whose parents provided consent to participate and who themselves provided assent. Each student was provided a space separated by black cardboard dividers in order to ensure that the students had privacy while completing the measures. The questionnaire package consisted of the SPPA and the PVGQ. 


\section{RESULTS}

All data were analyzed using SPSS version 22. Data were first screened for missing values. A total of 147 (18\%) participants submitted incomplete but valid questionnaires based on the inclusion criteria previously described. The percentage of missing values for the PVGQ measure and each of the SPPA subscales did not exceed 5\%. Although Little's Test (Little, 1988) did not provide evidence that the omitted values were missing completely at random $\left(\chi^{2}(3290)=3742.27, p<.001\right)$, a thorough review of the data did not reveal an observable pattern for the missing values. Therefore, the missing values were assumed to be missing at random suggesting the missing values may be estimated using a number of methods. Following the estimation of the missing values using the regression method available on SPSS, data were inspected for outliers and violations of normality. A total of 58 univariate outliers were identified and excluded from any subsequent analyses. No multivariate outliers were found following the exclusion of the univariate outliers. Finally, departures from normality were evaluated using the skew statistic. No significant departures from normality were observed. The final sample included 758 Grade 7 adolescents (55.1\% Female; $M_{\text {age }}=12.34$ years; $S D=0.49$ ).

The first hypothesis was exploratory in nature expecting PVGU to be negatively associated with at least one or more domains of self-perception. These associations were assessed in two steps. First, bivariate correlations were conducted to assess the associations between PVGU and domains of self-perception. Given the quantity of correlations calculated, a modified alpha was used to test for significance based on the Bonferroni method (i.e., .05/28 =.002). Next, the domains of selfperception shown to be significantly negatively correlated with reports of PVGU were included as possible predictors of PVGU in a planned linear regression model. Reports of self-perception within the scholastic competence $(r(756)=-.15, p<.001)$, behavioural conduct $(r(756)=-.33, p<.001)$, close friendship $(r(756)=-.18, p<.001)$, and self-worth $(r(756)=-.18, p<.001)$ domains significantly correlated with PVGU, and were therefore included in the linear regression model. Results from the linear regression model demonstrated perceptions of self within the included domains predicted $\operatorname{PVGU}(F(4,753)=24.39, p<.001)$ accounting for $11.5 \%$ of the variance. Specifically, perceptions of self within the behavioural conduct $(\beta=-.31, p<.001)$ and close friendship domains $(\beta=-.08, p=$ $.04)$ emerged as significant negative predictors of PVGU. These results support the prediction of H1, however, because only two domains emerged as predictors, these findings only partially support $\mathrm{H} 1$.

It was further hypothesized that differences in reported perceptions of self would be observed between males and females within the athletic competence, physical appearance, and close friendship domains (H2) as well as across the PVGU classifications, whereby, individuals reporting higher levels of PVGU would report lower perceptions of self in at least one or more domains (H3). Notably, no hypothesis was made with regard to the interaction between gender and the PVGU classifications. A 2 (Gender: Male, Female) x 4 (PVGU Classifications: None, Minimal, At-Risk, Problematic) multivariate analysis of variance was conducted for the domains of self-perception. The results revealed significant main effects for gender (Wilk's Lambda $=.89, F(7,744)=13.27, p<.001, \eta_{p}{ }^{2}$ $=.11$ ) and PVGU classifications (Wilk's Lambda $\left.=.88, F(21,2136.92)=4.95, p<.001, \eta_{p}{ }^{2}=.04\right)$. Further, the interaction between gender and PVGU classifications was significant (Wilk's Lambda $\left.=.95, F(21,2136.92)=1.71, p=.02, \eta_{p}^{2}=.02\right)$. The results of the univariate and post-hoc analyses are explained in further detail below.

Significant univariate analyses for gender were observed within the athletic competence $(F(1,757)$ $\left.=27.35, p<.001, \eta_{p}{ }^{2}=.04\right)$, behavioural conduct $\left(F(1,757)=13.82, p<.001, \eta_{p}{ }^{2}=.02\right)$, close friendship $\left(F(1,757)=19.76, p<.001, \eta_{p}^{2}=.03\right)$, and physical appearance domains $(F(1,757)=$ $\left.14.88, p<.001, \eta_{p}{ }^{2}=.02\right)$. These findings demonstrate that males perceive a higher sense of self within the athletic competence (Males: $M=15.53, S D=3.81$; Females: $M=13.56, S D=4.10$ ) and physical appearance (Males: $M=15.64, S D=3.38$; Females: $M=14.49, S D=3.93$ ) domains, whereas females report greater perceptions of self in the behavioural conduct (Males: $M=15.67$, $S D=2.92$; Females: $M=17.03, S D=2.90$ ) and close friendship (Males: $M=16.42, S D=3.37$; Females: $M=17.78, S D=2.67$ ) domains. Thus, $\mathrm{H} 2$ was largely supported even though the gender difference observed in the behavioural conduct domain was not anticipated. 
Significant univariate analyses for PVGU classifications were observed within the behavioural conduct $\left(F(3,755)=22.11, p<.001, \eta_{p}^{2}=.08\right)$, close friendships $\left(F(3,755)=2.79, p=.04, \eta_{p}{ }^{2}=\right.$ $.01)$, physical appearance $\left(F(3,755)=7.56, p<.001, \eta_{p}^{2}=.03\right)$, scholastic competence $(F(3,755)=$ $\left.4.90, p=.002, \eta_{p}{ }^{2}=.02\right)$, and self-worth domains $\left(F(3,755)=10.86, p<.001, \eta_{p}{ }^{2}=.04\right)$. Results of post-hoc tests (i.e., Tukey) revealed participants classified as Problematic reported lower perceptions of self in the scholastic competence, behavioural conduct, close friendship, and self-worth domains compared to those classified as None and Minimal. Problematic gamers reported lower perceptions of self compared to At-Risk gamers within the behavioural conduct and close friendships domains, but did not report significantly different levels of self-perception within the scholastic competence or self-worth domains. Finally, within the physical appearance domain, no differences in perceptions of self were found for those classified as None, At-Risk, and Problematic, however, participants in the Minimal classification reported higher levels than the other three classifications. Averages for each domain of self-perception across PVGU classifications are presented in Table 1. With the exception of the physical appearance domain, the results largely support $\mathrm{H} 3$.

Significant Gender x PVGU Classification interactions were also observed for both the behavioural conduct $\left(F(3,755)=2.99, p=.03, \eta_{p}^{2}=.01\right)$ and self-worth domains $(F(3,755)=4.08, p=.007$, $\left.\eta_{p}^{2}=.02\right)$. Figure 1 graphically presents the interaction for the behavioural conduct and self-worth domains, respectively. Within the behavioural conduct domain, the gender difference present within classifications representing lower levels of PVGU disappears within groups representing greater levels of PVGU. On the other hand, the interaction within the self-worth domain presented a different pattern. Reports of self-worth for both males and females were lower within classifications representing greater PVGU; however, for females, self-worth was higher within the Problematic group than the At-Risk Group.

\section{DISCUSSION}

The present study explored the associations between adolescents' PVGU and perceptions of self within a variety of domains relevant to the period of adolescence, as well as the differences in perceptions of self across varying level of PVGU severity. Results from this study demonstrate greater PVGU is associated with poorer perceptions of self within the behavioural conduct and close friendship domains, and that problematic gamers report lower perceptions of self within the scholastic competence,

Table 1. Means, Standard Deviations and Total Counts for all Self-Perception Domains Across Problematic Gaming Classifications

\begin{tabular}{|c|c|c|c|c|c|c|c|c|c|c|c|c|}
\hline & \multicolumn{3}{|c|}{ None } & \multicolumn{3}{|c|}{ Minimal } & \multicolumn{3}{|c|}{ At-Risk } & \multicolumn{3}{|c|}{ Problematic } \\
\hline & $M$ & $S D$ & $N$ & $M$ & $S D$ & $N$ & $M$ & $S D$ & $N$ & $M$ & $S D$ & $N$ \\
\hline Scholastic Competence & $15.76^{\mathrm{a}}$ & 3.02 & 151 & $15.82^{\mathrm{a}}$ & 3.23 & 324 & $15.13^{\mathrm{a}, \mathrm{b}}$ & 3.19 & 192 & $14.38^{\mathrm{b}}$ & 3.09 & 91 \\
\hline Social Competence & 17.04 & 2.73 & 151 & 16.28 & 2.80 & 324 & 16.08 & 2.93 & 192 & 15.98 & 2.81 & 91 \\
\hline Athletic Competence & 14.66 & 4.00 & 151 & 14.46 & 4.13 & 324 & 14.27 & 4.33 & 192 & 14.39 & 3.60 & 91 \\
\hline Physical Appearance & $14.99^{\mathrm{a}}$ & 3.87 & 151 & $15.52^{\mathrm{b}}$ & 3.56 & 324 & $14.49^{\mathrm{a}}$ & 3.93 & 192 & $14.28^{\mathrm{a}}$ & 3.51 & 91 \\
\hline Behavioral Conduct & $17.27^{\mathrm{a}}$ & 2.99 & 151 & $16.94^{\mathrm{a}}$ & 2.70 & 324 & $16.06^{\mathrm{b}}$ & 2.92 & 192 & $13.95^{\mathrm{c}}$ & 2.70 & 91 \\
\hline Close Friendships & $17.80^{\mathrm{a}}$ & 2.78 & 151 & $17.36^{\mathrm{a}}$ & 2.84 & 324 & $16.97^{\mathrm{a}}$ & 3.27 & 192 & $15.90^{\mathrm{b}}$ & 3.57 & 91 \\
\hline Self-Worth & $17.35^{\mathrm{a}}$ & 3.05 & 151 & $17.52^{\mathrm{a}}$ & 2.69 & 324 & $16.47^{\mathrm{b}}$ & 3.12 & 192 & $15.84^{\mathrm{b}}$ & 2.83 & 91 \\
\hline
\end{tabular}

Note: Significant differences $(p<.05)$ across PVGU classifications are indicated by a different letter superscript in the total row of each domain. This was only done for the domains where a significant univariate analysis was observed (i.e., Behavioral Conduct, Close Friendship, Physical Appearance, Scholastic Competence, and Self-Worth). 
Figure 1. Mean scores in the behavioural conduct (a) and self-worth (b) domains of self-perception for students classified in each of the four problematic gaming groups between males and females

a)

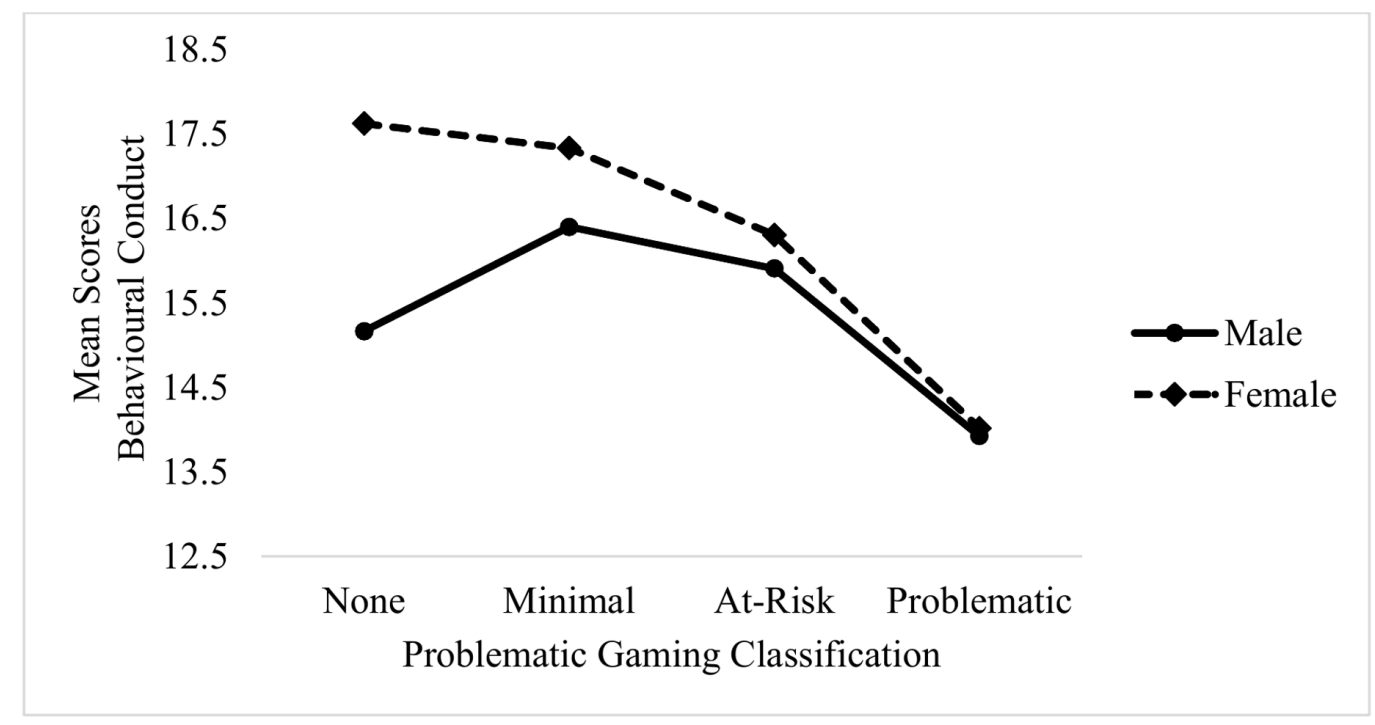

b)

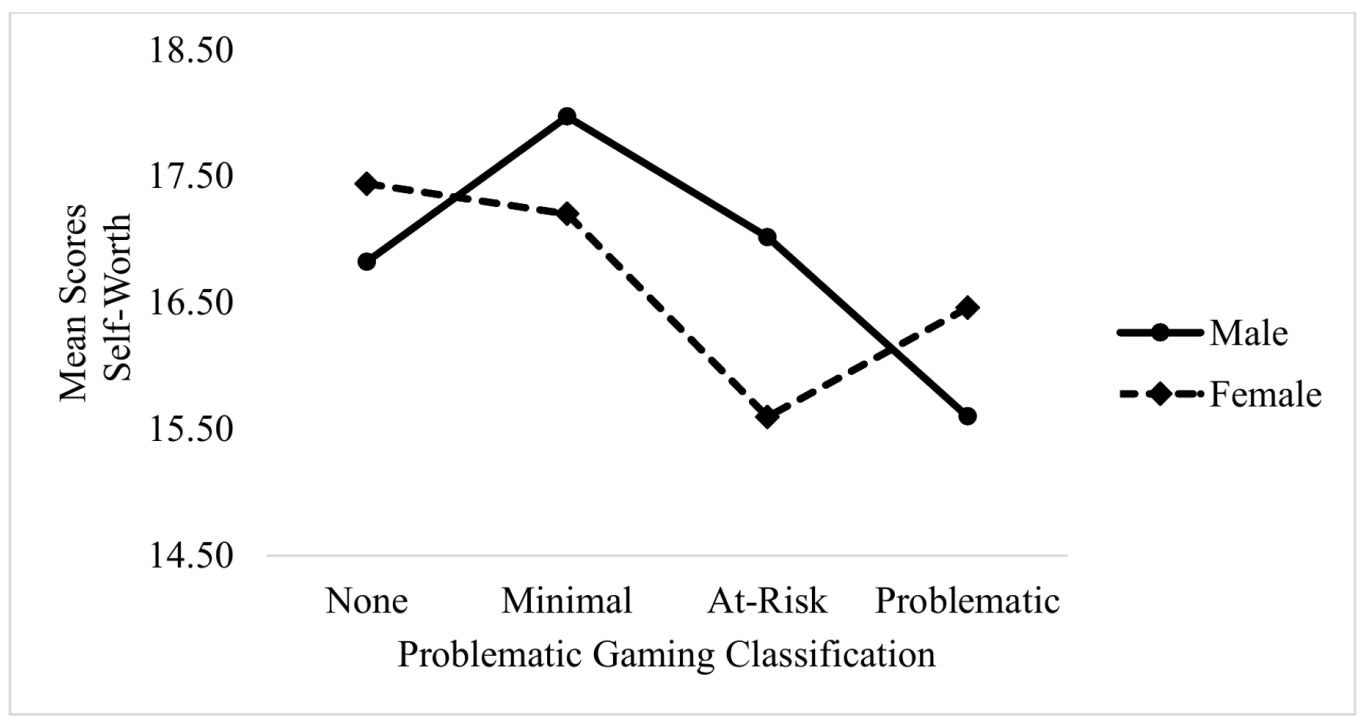

behavioural conduct, close friendship, and self-worth domains. Additionally, two gender by PVGU severity interactions were observed. Within the behavioural conduct domain, it was observed that gender differences fade away within classifications representing greater PVGU. Within the self-worth (i.e., self-esteem) domain, a subtle increase for females was observed within the highest level of PVGU severity, whereas males reported a gradual decrease in their reported self-worth. These results are discussed within the context of previous literature. 


\section{PVGU and Self-Perceptions}

This is the first study to demonstrate a cross-sectional association between PVGU and specific domains of self-perception. Consistent with previous research demonstrating PVGU is associated with a decline in academic engagement (Rehbein et al., 2015), overall self-esteem (Lemmens et al., 2011), as well as an increase in feelings of loneliness (Lemmens et al., 2011) and behavioural difficulties (Frölich et al., 2016), it was observed that higher levels of PVGU were associated with poorer perceptions of self within the scholastic competence, self-worth, close friendship, and behavioural conduct domains. However, several domains of self-perception (i.e., social acceptance, athletic competence, physical appearance) did not correlate with reports of PVGU. These non-significant results challenge the stereotype described by Williams and colleagues (2008) of a gamer as an anti-social, non-athletic, unattractive adolescent male.

Furthermore, the results indicate that adolescents' reports of their self-perception within the behavioural conduct domain and, to a smaller extent, the close friendship domain are of particular importance when examining PVGU. The behavioural conduct domain assesses the extent to which adolescents perceive their behaviour as appropriate within their immediate environment. Thus, adolescents perceiving their behaviour as incorrect or not meeting expectations within their immediate environment were found to be more likely to report higher levels of PVGU. However, this should not be interpreted as evidence suggesting PVGU is associated with an increase in poor behaviour per se, but that PVGU is associated with the perception that one's behaviour is inappropriate or misunderstood. This perspective suggests the draw toward video games is the provision of an environment in which individuals' behaviour is accepted, which parallels the emerging literature examining the link between PVGU symptoms and self-regulation disorders such as attention deficit hyperactive disorder (Hyun et al., 2015; Strittmatter et al., 2015). Future research should explore the association between PVGU and reports of self-perception within the behavioural conduct domain while controlling for reports of symptoms of self-dysregulation.

The association between PVGU and perceptions of self within the close friendship domain points toward increasing issues with the development and maintenance of quality relationships for adolescents struggling with PVGU. Importantly, the social acceptance domain, which was found to not correlate with PVGU, differs from the close friendship domain in that one may feel capable in interacting with others, but not able to initiate and support a close friendship. This contrast between these domains, therefore, is not perceived to be contradictive in the findings, but a subtle difference in how individuals struggling with PVGU comprehend their abilities within the social context. Underlying the association between PVGU and the close friendship domain might be the experience of conflict within peer or family relationships, but not threatening their perception of being able to interact with or perceive a level of acceptance by others. Lemmens and colleagues (2015) found reports of conflict within one's relationships with friends, family, or partners due to gaming provided the highest diagnostic accuracy. The experience of such conflict might additionally increase individuals' preference to interact online, which has been found to predict a weakened ability to regulate video game use, resulting in greater PVGU (Caplan, 2003; 2010; Haagsma, Caplan, Peters, \& Pieterse, 2013; Liu \& Peng, 2009). The lack of larger effect size for this association may be indicative of the obvious differences between individuals' perception of their ability to begin and maintain close friendships versus the experience of conflict in relationships, which may be perceived as unrelated to their abilities. An interesting area for future research would be to examine whether change in this variable predicts a fluctuation in the level of PVGU.

The present study was also able to explore differences in self-perception across varying classifications of PVGU. Individuals reporting high PVGU (i.e., Problematic group) additionally reported lower perceptions of self within the behavioural conduct, close friendship, physical appearance, and scholastic domains as well as a poorer sense of self-worth (i.e., self-esteem). Although the inclusion of a None Group provided a comparison group, the four created PVGU groups may be reduced to three as the differences in self-perception between the None and Minimal Groups never 
reached significance, except for a nuanced finding in the physical appearance domain, suggesting these particular groups could be collapsed into one group. The use of three groups is in line with a proposal by Sim and colleagues (2012) which mirrors the severity levels used in assessing gambling disorder within the DSM-5 (APA, 2013). The subtle differences observed between the At-Risk and Problematic Group within the behavioural conduct and close friendship domains were of particular interest as they suggest the possibility that the profile of an At-Risk gamer changes to that of a Problematic gamer with a decrease in self-perception within these domains. The present study was limited by a cross-sectional design that did not allow this particular hypothesis to be tested. Future research should examine this association through more sophisticated research designs in order to address whether or not changes in these two domains correspond to an increase in PVGU.

The differences in self-perception across the four PVGU groups were additionally found to fluctuate as a function of gender. Although gender differences are consistent within both the gaming (Gentile et al., 2011) and self-perception literature (Wilgenbusch \& Merrell, 1999), these findings suggest that the interaction of gender differences within these two fields yield contrasting selfperception profiles. The first interaction was observed within the behavioral domain. As shown in Figure 1a, the gender advantage for females disappears within groups representing greater PVGU severity. This provides important information regarding the risk of worrisome behavioural patterns across both males and females in terms of reported PVGU.

The second interaction was observed within the self-worth domain. Similar to the first interaction, Figure $1 \mathrm{~b}$ shows an overall pattern of decline in the reports of self-worth as PVGU severity increases for both males and females. However, for females, reports of self-worth increased for those included in the Problematic Group compared to those in the At-Risk Group. Although further research is necessary to understand the nuances underlying this result, it is possible that a greater level of social support from gaming is perceived for females in the Problematic Group alluding to an increase in overall self-worth (Collins \& Freeman, 2013; Kowert \& Oldmeadow, 2014). Further research is necessary to explore this relation in more detail.

Several limitations of the present study should be noted. First, the use of self-report data relies on the honesty of participants and their self-understanding, which presents a possible bias in the data. While all of the instruments and corresponding subscales demonstrated adequate internal consistency, this limitation is still unavoidable in self-report data. Second, this study did not explicitly define video games to the participants as any game played on electronic devices. Therefore, it is likely there may be more adolescents who play video games and possibly experience some symptoms of PVGU, but did not report any because the games they play were not perceived as meeting a preconceived definition of video games. Finally, the use of cross-sectional data prohibits the ability to suggest causation. Future research would do well to use the findings from the present study to build a more sophisticated longitudinal study addressing change in self-perception as a potential predictor of PVGU. These limitations notwithstanding, the results of the present study are of interest in understanding the possible motivation for playing video games from the perspective of adolescents' perception of competence.

\section{CONCLUSION}

The present study builds on previous research and the growing interest in problematic gaming. It is the first to reveal significant and meaningful links between PVGU and perceptions of self within a variety of domains associated with the period of adolescence. The results suggest several domains of selfperception, notably behavioural conduct and close friendships, may either facilitate the development 
of PVGU or make up some of the outcomes associated with PVGU. Future research is necessary to better understand these associations. Finally, the present findings presented subtle differences in the self-perception profile for males and females struggling with greater PVGU severity implying future research should not address such associations in isolation from reports of gender. Overall, these findings contribute to literature seeking to better understand adolescents' PVGU.

\section{REFERENCES}

American Psychiatric Association. (2013). Diagnostic and statistical manual of mental disorders (5th ed.). Washington, DC: Author.

Anderson, C. A., Shibuya, A., Ihori, N., Swing, E. L., Bushman, B. J., Sakamoto, A., \& Saleem, M. et al. (2010). Violent video game effects on aggression, empathy, and prosocial behavior in Eastern and Western countries: A meta-analytic review. Psychological Bulletin, 136(2), 151-173. doi:10.1037/a0018251 PMID:20192553

Bowman, N. D., Kowert, R., \& Cohen, E. (2015). When the ball stops, the fun stops too: The impact of social inclusion on video game enjoyment. Computers in Human Behavior, 53, 131-139. doi:10.1016/j.chb.2015.06.036

Bushman, B. J., \& Anderson, C. A. (2002). Violent video games and hostile expectations: A test of the general aggression model. Personality and Social Psychology Bulletin, 28(12), 1679-1686. doi:10.1177/014616702237649

Caplan, S. E. (2003). Preference for online social interaction: A theory of problematic Internet use and psychosocial well-being. Communication Research, 30(6), 625-648. doi:10.1177/0093650203257842

Caplan, S. E. (2010). Theory and measurement of generalized problematic Internet use: A two-step approach. Computers in Human Behavior, 26(5), 1089-1097. doi:10.1016/j.chb.2010.03.012

Collins, E., \& Freeman, J. (2013). Do problematic and non-problematic video game players differ in extraversion, trait empathy, social capital and prosocial tendencies? Computers in Human Behavior, 29(5), 1933-1940. doi:10.1016/j.chb.2013.03.002

Desai, R. A., Krishnan-Sarin, S., Cavallo, D., \& Potenza, M. N. (2010). Video-gaming among high school students: Health correlates, gender differences, and problematic gaming. Pediatrics, 126(6), e1414-e1424. doi:10.1542/peds.2009-2706 PMID:21078729

Durkin, K., \& Barber, B. (2002). Not so doomed: Computer game play and positive adolescent development. Journal of Applied Developmental Psychology, 23(4), 373-392. doi:10.1016/S0193-3973(02)00124-7

Entertainment Software Association. (2013). 2014: Sales, demographic, and usage data: Essential facts about the computer and video game industry. Retrieved from http://www.theesa.com/wp-content/uploads/2014/10/ ESA_EF_2014.pdf

Evans, D. W., Noam, G. G., Wertlieb, D., Paget, K. F., \& Wolf, M. (1994). Self-perception and adolescent psychopathology: A clinical-developmental perspective. The American Journal of Orthopsychiatry, 64(2), 293-300. doi:10.1037/h0079514 PMID:8037237

Frölich, J., Lehmkuhl, G., Orawa, H., Bromba, M., Wolf, K., \& Görtz-Dorten, A. (2016). Computer game misuse and addiction of adolescents in a clinically referred study sample. Computers in Human Behavior, 55, 9-15. doi:10.1016/j.chb.2015.08.043

Funk, J. B., \& Buchman, D. D. (1996). Playing violent video and computer games and adolescent self-concept. Journal of Communication, 46(2), 19-32. doi:10.1111/j.1460-2466.1996.tb01472.x

Gentile, D. A. (2009). Pathological video-game use among youth ages 8 to 18: A national study. Psychological Science, 20(5), 594-602. doi:10.1111/j.1467-9280.2009.02340.x PMID:19476590

Gentile, D. A., Choo, H., Liau, A., Sim, T., Li, D., Fung, D., \& Khoo, A. (2011). Pathological video game use among youths: A two-year longitudinal study. Pediatrics, 127(2), e319-e329. doi:10.1542/peds.2010-1353 PMID:21242221

Granic, I., Lobel, A., \& Engels, R. C. M. E. (2013). The benefits of playing video games. Advance on American Psychologist. 
Griffiths, M. (2005). A components model of addiction within a biopsychosocial framework. Journal of Substance Use, 10(4), 191-197. doi:10.1080/14659890500114359

Griffiths, M. (2009). The role of context in online gaming excess and addiction: Some case study evidence. International Journal of Mental Health and Addiction, 8(1), 119-125. doi:10.1007/s11469-009-9229-x

Haagsma, M., Caplan, S., Peters, O., \& Pieterse, M. (2013). A cognitive-behavioral model of problematic online gaming in adolescents aged 12-22 years. Computers in Human Behavior, 29(1), 202-209. doi:10.1016/j. chb.2012.08.006

Harter, S. (1988). Manual for the self-perception profile for adolescents. Denver, CO.

Harter, S. (1990). Causes, correlates, and the functional role of global self-worth: A life-span perspective. In R. J. Sternberg \& J. J. Kolligian (Eds.), Competence Considered (pp. 67-97). New Haven: Yale University.

Harter, S. (1997). The personal self in social context: Barriers to authenticity. In R. D. Ashmore \& L. Jussim (Eds.), Self and identity: Fundamental issues (pp. 81-105).

Harter, S. (2003). The development of self representation during childhood and adolescence. In M. R. Leary \& J. P. Tangney (Eds.), Handbook of Self and Identity (pp. 610-642). New York City: The Guilford Press.

Harter, S. (2011). Emerging self-processes during childhood and adolescence. In M. R. Leary \& J. P. Tangney (Eds.), Handbook of self and identity. New York: Guilford Press.

Hastings, E. C., Karas, T. L., Winsler, A., Way, E., Madigan, A., \& Tyler, S. (2009). Young childrens video/ computer game use: Relations with school performance and behavior. Issues in Mental Health Nursing, 30(10), 638-649. doi:10.1080/01612840903050414 PMID:19742374

Hyun, G. J., Han, D. H., Lee, Y. S., Kang, K. D., Yoo, S. K., Chung, U.-S., \& Renshaw, P. F. (2015). Risk factors associated with online game addiction: A hierarchical model. Computers in Human Behavior, 48, 706-713. doi:10.1016/j.chb.2015.02.008

Jackson, L. A., von Eye, A., Fitzgerald, H. E., Zhao, Y., \& Witt, E. A. (2010). Self-concept, self-esteem, gender, race and information technology use. Computers in Human Behavior, 26(3), 323-328. doi:10.1016/j. chb.2009.11.001

King, D. L., Haagsma, M. C., Delfabbro, P. H., Gradisar, M., \& Griffiths, M. D. (2013). Toward a consensus definition of pathological video-gaming: A systematic review of psychometric assessment tools. Clinical Psychology Review, 33(3), 331-342. doi:10.1016/j.cpr.2013.01.002 PMID:23396015

Ko, C.-H., Yen, J.-Y., Chen, C.-C., Chen, S.-H., \& Yen, C.-F. (2005). Gender differences and related factors affecting online gaming addiction among Taiwanese adolescents. The Journal of Nervous and Mental Disease, 193(4), 273-277. doi:10.1097/01.nmd.0000158373.85150.57 PMID:15805824

Kowert, R., Domahidi, E., Festl, R., \& Quandt, T. (2014). Social gaming, lonely life? The impact of digital game play on adolescents social circles. Computers in Human Behavior, 36, 385-390. doi:10.1016/j.chb.2014.04.003

Kowert, R., \& Oldmeadow, J. (2014). Playing for social comfort: Online video game play as a social accommodator for the insecurely attached. Computers in Human Behavior, 53, 556-566. doi:10.1016/j.chb.2014.05.004

Lemmens, J. S., Valkenburg, P. M., \& Gentile, D. A. (2015). The Internet Gaming Disorder Scale. Psychological Assessment, 27(2), 567-582. doi:10.1037/pas0000062 PMID:25558970

Lemmens, J. S., Valkenburg, P. M., \& Peter, J. (2011). Psychosocial causes and consequences of pathological gaming. Computers in Human Behavior, 27(1), 144-152. doi:10.1016/j.chb.2010.07.015

Little, R. (1988). A test of missing completely at random for multivariate data with missing values. Journal of the American Statistical Association, 83(404), 1198-1202. doi:10.1080/01621459.1988.10478722

Liu, M., \& Peng, W. (2009). Cognitive and psychological predictors of the negative outcomes associated with playing MMOGs (massively multiplayer online games). Computers in Human Behavior, 25(6), 1306-1311. doi:10.1016/j.chb.2009.06.002

Marsh, H., \& Shavelson, R. (1985). Self-concept: Its multifaceted, hierarchical structure. Educational Psychologist, 20(3), 107-123. doi:10.1207/s15326985ep2003_1 
Mitchell, J. A., Rodriguez, D., Schmitz, K. H., \& Audrain-McGovern, J. (2013). Greater screen time is associated with adolescent obesity: A longitudinal study of the BMI distribution from Ages 14 to 18. Obesity (Silver Spring, Md.), 21(3), 572-575. doi:10.1002/oby.20157 PMID:23592665

Petry, N. M., Rehbein, F., Gentile, D. A., Lemmens, J. S., Rumpf, H.-J., Mößle, T., \& OBrien, C. P. et al. (2014). An international consensus for assessing internet gaming disorder using the new DSM-5 approach. Addiction (Abingdon, England), 109(9), 1399-1406. doi:10.1111/add.12457 PMID:24456155

Rehbein, F., Kleimann, M., \& Mössle, T. (2010). Prevalence and risk factors of video game dependency in adolescence: Results of a German nationwide survey. Cyberpsychology, Behavior, and Social Networking, 13(3), 269-277. doi:10.1089/cyber.2009.0227 PMID:20557246

Rehbein, F., Kliem, S., Baier, D., Mößle, T., \& Petry, N. M. (2015). Prevalence of Internet Gaming Disorder in German adolescents: Diagnostic contribution of the nine DSM-5 criteria in a statewide representative sample. Addiction (Abingdon, England), 110(5), 842-851. doi:10.1111/add.12849 PMID:25598040

Sim, T., Gentile, D. A., Bricolo, F., Serpelloni, G., \& Gulamoydeen, F. (2012). A conceptual review of research on the pathological use of computers, video games, and the internet. International Journal of Mental Health and Addiction, 10(5), 748-769. doi:10.1007/s11469-011-9369-7

Spekman, M. L. C., Konijn, E. A., Roelofsma, P. H. M. P., \& Griffiths, M. D. (2013). Gaming addiction, definition and measurement: A large-scale empirical study. Computers in Human Behavior, 29(6), 2150-2155. doi:10.1016/j.chb.2013.05.015

Strittmatter, E., Kaess, M., Parzer, P., Fischer, G., Carli, V., Hoven, C. W., \& Wasserman, D. et al. (2015). Pathological Internet use among adolescents: Comparing gamers and non-gamers. Psychiatry Research, 228(1), 128-135. doi:10.1016/j.psychres.2015.04.029 PMID:25959265

Tejeiro Salguero, R. A., \& Bersabé Morán, R. M. (2002). Measuring problem video game playing in adolescents. Addiction (Abingdon, England), 97(12), 1601-1606. doi:10.1046/j.1360-0443.2002.00218.x PMID:12472644

Wilgenbusch, T., \& Merrell, K. W. (1999). Gender differences in self-concept among children and adolescents: A meta-analysis of multidimensional studies. School Psychology Quarterly, 14(2), 101-120. doi:10.1037/h0089000

Williams, D., Yee, N., \& Caplan, S. E. (2008). Who plays, how much, and why? Debunking the stereotypical gamer profile. Journal of Computer-Mediated Communication, 13(4), 993-1018. doi:10.1111/j.1083-6101.2008.00428.x

Devin Mills is a PhD Candidate at McGill University with an interest in the application of Self-Determination Theory to the study of adaptive and maladaptive functioning. He is a current member of the Development and Intrapersonal Resilience Research Team.

Jessica Mettler is a MA student at McGill University with an interest in stress and coping in youth. She is a current member of the Development and Intrapersonal Resilience Research Team.

Michael Sornberger, PhD is a recent graduate of McGill University and currently works as a clinician in Calgary, Alberta. His research interests largely surround adolescents' problematic use of video games.

Nancy Heath, PhD, is a James McGill Professor in the Department of Educational and Counselling Psychology at McGill University. Her research program explores resilience and adaptive functioning in young people at-risk (children, adolescents, and young adults). She is a founding member, and past President, of the International Society for the Study of Self-Injury (ISSS), and director of the Development and Intrapersonal Resilience Research Team. 